\title{
Resumption of Trastuzumab in Patients With Disease Recurrence After (Neo-) Adjuvant Anti-HER2-therapy in Patients With HER2-positive Breast Cancer
}

\author{
LARS CHRISTIAN HANKER ${ }^{1}$, FRANK FÖRSTER ${ }^{2}$, JAN SCHRÖDER ${ }^{3}$, ANDREA GRAFE ${ }^{4}$, \\ THOMAS HITSCHOLD ${ }^{5}$, TOBIAS HESSE ${ }^{6}$, CLAUS RICHARD LATTRICH $^{7}$ and ACHIM RODY ${ }^{1}$ \\ ${ }^{1}$ Gynecology and Obstetrics Department, University of Schleswig-Holstein, Campus Lübeck, Lübeck, Germany; \\ ${ }^{2}$ Center for Gynecological Oncology and Palliative Medicine, University of Applied Sciences, Chemnitz, Germany; \\ ${ }^{3}$ Hematology and Oncology Practice, Mülheim an der Ruhr, Germany; \\ ${ }^{4}$ Health Care Center Nordhausen gGmbH, Nordhausen, Germany; \\ ${ }^{5}$ Klinikum Worms gGmbH, Worms, Germany; \\ ${ }^{6}$ Gynecology Department, Agaplesion Diakonieklinikum, Rotenburg an der Wümme, Germany; \\ ${ }^{7}$ Roche Pharma AG, Grenzach, Germany
}

\begin{abstract}
Background/Aim: HER2-positive breast cancers eventually relapse in about one third of patients. Is anti-HER2directed therapy with Herceptin ${ }^{\circledR}$ (trastuzumab) effective in retreatment? Between 2008 and 2018, 216 patients with recurrent HER2-positive breast cancer (BC) were re-treated with Herceptin (HER) during first-line therapy. This study assessed the effectiveness and tolerability of re-treatment with HER. Patients and Methods: After approval from Ethical committee, the NIS was conducted according to German Drug Act. Retreatment with HER was documented at routine visits starting with a basic observational period of maximum 12 months and a follow-up period of maximum additional four years. Results: HER2-positive BC relapsed after a median of 36.5 months (mos). Patients were re-treated with HER +/- chemotherapy $+/$ - endocrine therapy. HER-containing regimens resulted in median progression-free survival ( $m P F S$ ) of 12.7 (95\% CI=10.514.8) mos and overall survival (OS-2) of 31.6 mos (95\% CI=28.8-38.4) since recurrence diagnosis. Differentiation of recurrence types (local, visceral, non-visceral) unfolded worst prognosis for patients with visceral metastases. Cardiac monitoring within this non-interventional study (NIS) did not
\end{abstract}

This article is freely accessible online.

Correspondence to: PD Lars Hanker, Gynecology and Obstetrics Department, Campus Lübeck, University of Schleswig-Holstein, Germany. Tel +49 45150041700, e-mail: Lars.Hanker@uksh.de

Key Words: HER2-positive, metastatic breast cancer, re-therapy, trastuzumab. result in new safety concerns. Conclusion: Re-therapy with HER in the first-line setting of advanced HER2-positive breast cancer is effective and without unexpected or intensified adverse events.

HER2-positive breast cancer is known to be aggressive and has a worse prognosis than HER2-negative forms of breast cancer (1-3). Therefore, patients with successful neo- and/or adjuvant therapies are at risk to eventually relapse. Risk factors for breast cancer recurrence like negative hormone receptor status, nuclear grade, or central nervous system (CNS) progression have been described (4). In 2000, Herceptin ${ }^{\circledR}$ (trastuzumab) was granted approval for the treatment of advanced HER2-positive breast cancer, based on the outcomes of several pivotal trials (5-7). Six years later, adjuvant and after another 3 years neo-adjuvant treatment with Herceptin (HER) was approved by the European medical authority (EMA) (8-10). Recurrence of HER2-positive breast cancer represents a special clinical condition within the advanced treatment situation. Usefulness of HER within this clinical situation was investigated and confirmed by the results of RHEA-study (11). After approval, therapies are administered in the dayto-day routine where the treatment population is less well defined. Therefore, this non-interventional study (NIS) investigated how results from clinical studies on the safety and efficacy of HER in HER2-positive breast cancer translate into routine clinical practice. Our goal was to evaluate re-treatment with HER in patients with recurrent HER2-positive breast cancer treated in clinics and outpatient practices in a real world (RW)-setting. Parameters of primary interest were effectiveness, cardiac and overall safety. 
Results of this NIS are matched with findings from the controlled RHEA study (11) and further outcomes for patients in the advanced treatment setting of HER2-positive breast cancer (1-3).

\section{Patients and Methods}

Between October 2008 and January 2013, 216 evaluable patients (analysis population, AP) with recurrent HER2-positive breast cancer in palliative first-line treatment were recruited in 122 gyneco-oncological practices or clinics throughout Germany. The AP reflects a patient population representative for the German patient care in the recurrent treatment setting. All participating patients provided their informed consent to participate in this NIS. Pre- or post-menopausal patients after effective anti-HER2 therapy with trastuzumab, with either local or metastatic disease recurrence and with adequate cardiac status were included into this observational study. Approval for this NIS with trial number ML21589 was obtained from the ethical committee of the University of Frankfurt/Main. No further formal specifications were made in terms of diagnosis, therapy, choice of therapeutic regimen, tumor assessment intervals or methods, as documentation of clinical day-to-day routine was gathered. The planned patient number of 250 recruited patients was based on an estimated progression-free survival (PFS) calculation referring to results of clinical trials (1) in the first line treatment of metastatic HER2-positive breast cancer, including an estimated loss-to-follow-up of about $20 \%$ (expected accuracy of the $95 \%$ CI for median PFS $=6 \pm 1$ months).

Basic observational interval comprised 12 months with a followup period of up to 4 years - resulting in about 5 years of observation. Attention was paid to the length of the interval between the first anti-HER2-treatment and the onset of first-line trastuzumab therapy [disease free survival (DFS)], duration of this re-therapy, therapy combinations and regimens used and reasons for the respective choices.

The primary effectiveness parameter was PFS under the condition of locally recurrent or metastatic HER2-positive breast cancer, specifically defined as time from diagnosis of local recurrent tumor/distant metastasis, leading to initiation of anti-HER 2 re-therapy with HER until anew progression or death due to any cause. Patients without an event (PD or death) before change of therapy or at the end of study participation were censored using the earliest date of either "date of change of therapy" or "date of last patient contact" or "date of last documented dose of Herceptin". Other parameters of interest were overall survival (OS), defined from initial tumor resection to death from any cause, and specifically for this observational study OS-2, defined as time from diagnosis of recurrence or metastasis to death of any cause, and overall response rate (ORR). Treatment modalities and combinations, treatment duration and modification within the special situation of a re-therapy setting as well as furtherline therapies were documented. The NIS collected adverse events (as of 2014 in part retroactively) and adverse drug reactions under daily clinical routine to possibly detect unknown or rare AEs.

All parameters were analyzed descriptively. Categorical variables are presented with absolute and relative frequencies; continuous variables with mean, standard deviation, minimum, median, maximum, and corresponding 95\% confidence interval (CI) where applicable. Time-to-event endpoints including PFS, OS, and OS-2 were estimated by using the Kaplan-Meier method (12) to present time-to-event data together with the number of censored cases as well as quartiles, rates, and corresponding 95\%CI. A multivariable logistic regression analysis and a multivariable Cox regression analysis were performed for the AP to identify potential factors (patient or tumor characteristics) affecting the clinical response rate (13).

Description of the retrospectively collected DFS between firstline therapy and recurrence, PFS, OS, OS-2, as well as cardiac and non-cardiac side effects and safety parameters based on patient characteristics and prognostic factors will be presented and discussed within this manuscript.

\section{Results}

Patients. First patient was included in October 2008, while the last patient's last visit occurred in January 2018. A total of 325 patients were screened, with 86 patients failing the screening procedure and 239 patients being enrolled in the study. Cardiac unimpaired patients with relapsing or recurrent HER2-positive breast cancer, that had successfully been treated with HER for early breast cancer and had not yet received any chemotherapeutic treatment against their disease recurrence, were eligible. Twenty-three patients were excluded from the AP $(n=216)$ on which the results are presented. Reasons for exclusion were chemotherapy for advanced disease before HER $(n=11)$, no prior systemic therapy with HER $(n=3)$, therapeutic setting inadequate $(n=2)$ or other violations of inclusion/exclusion criteria $(n=7)$.

Table I depicts the baseline patient characteristics at primary diagnosis for the total population and for the subgroups according to the therapeutic regimen received during the NIS. HER2-positive receptor status was documented for all patients, hormone receptor status was positive in $54.6 \%$ of the AP, median age was 56.1 years (range $=22.3-85.3$ years). Half of the patients had one or more comorbidities, $88 \%$ had an invasive ductal tumor, $36 \%$ with a DCIS component (Table I).

Retrospective data collection with respect to treatment of HER2-positive early breast cancer. All patients underwent surgery [189 (87.5\%) R0 resection] (Table I), $186(86.1 \%)$ received radiotherapy, $141(65.3 \%)$ of the 216 patients were treated with adjuvant chemotherapy, $106(49.1 \%)$ received adjuvant endocrine therapy. A total of 205 (94.9\%) patients received HER in the adjuvant setting (Table II), including those with maintenance from neo-adjuvant treatment.

Derived from retrospective data collection, median left ventricular ejection fraction (LVEF) remained stable with a median of $65 \%$ and $65 \%$, or a mean of $65.7 \%$ and $64.4 \%$ before and after treatment of early breast cancer with HER, respectively.

Treatment patterns. The median duration $(95 \% \mathrm{CI})$ of the total observational period within this NIS was 59.3 mos (range=57.3-59.9 mos). HER re-treatment due to progression of HER2-positive breast cancer was initiated after a median DFS of 36.5 mos (range=8.0-135.1 mos). The decision for 
Hanker et al: Resumption of Trastuzumab in Patients With Disease Recurrence After (Neo-) Adjuvant Anti-HER2-Therapy

Table I. Baseline characteristics at study entry and according to first-line palliative treatment regimen (AP).

\begin{tabular}{|c|c|c|c|c|c|c|}
\hline Parameter & $\begin{array}{c}\text { Total } \\
\mathrm{n}=216\end{array}$ & $\begin{array}{l}\text { HER mono } \\
\text { re-therapy } \\
n=36\end{array}$ & $\begin{array}{c}\text { Taxanes } \\
\mathrm{n}=51\end{array}$ & $\begin{array}{c}\text { Endocrine } \\
\text { therapy } \\
n=35\end{array}$ & $\begin{array}{c}\text { Other CTx } \\
n=74\end{array}$ & $\begin{array}{c}\text { CTx and } \\
\text { endocrine therapy } \\
n=20\end{array}$ \\
\hline $\begin{array}{l}\text { Age (years), } \\
\text { Median, (min; max) }\end{array}$ & $56.1(22.3 ; 85.3)$ & $57.4(32.5 ; 85.3)$ & $58.0(36.5 ; 79.5)$ & $49.0(31.4 ; 78.2)$ & $57.4(29.0 ; 83.4)$ & $55.1(22.3 ; 75.8)$ \\
\hline BMI $\left(\mathrm{kg} / \mathrm{m}^{2}\right) \mathrm{n}=$ & 215 & 35 & 51 & 35 & 74 & 20 \\
\hline Median, (min; max) & $25.8(16.3 ; 45.6)$ & $25.0(16.7 ; 43.7)$ & $25.9(19.0 ; 36.7)$ & $25.7(19.6 ; 42.2)$ & $26.1(16.3 ; 44.6)$ & $27.1(19.3 ; 45.6)$ \\
\hline $\begin{array}{l}\text { Comorbidities/ } \\
\geq 1 \text { comorbidity, n (\%) }\end{array}$ & $108(50.0)$ & $15(41.7)$ & $31(60.8)$ & $16(45.7)$ & $37(50.0)$ & $9(45.0)$ \\
\hline \multicolumn{7}{|l|}{$\begin{array}{l}\text { Charlson comorbidity } \\
\text { index, } \mathrm{n}(\%)\end{array}$} \\
\hline 0 & $169(78.2)$ & $25(69.4)$ & $44(86.3)$ & $30(85.7)$ & $54(73.0)$ & $16(80.0)$ \\
\hline 1 & $27(12.5)$ & $7(19.4)$ & $6(11.8)$ & $3(8.6)$ & $9(12.2)$ & $2(10.0)$ \\
\hline 2 & $14(6.5)$ & $3(8.3)$ & $1(2.0)$ & $2(5.7)$ & $7(9.5)$ & $2(10.0)$ \\
\hline 3 & $5(2.3)$ & $1(2.8)$ & 0 & 0 & $3(4.1)$ & $1(5.0)$ \\
\hline 4 & $1(0.5)$ & 0 & 0 & 0 & $1(1.4)$ & 0 \\
\hline \multicolumn{7}{|l|}{$\begin{array}{l}\text { Location of the } \\
\text { primary tumor, } \mathrm{n}(\%)\end{array}$} \\
\hline Left & $111(51.4)$ & $17(47.2)$ & $23(45.1)$ & $23(65.7)$ & $42(56.8)$ & $6(30.0)$ \\
\hline Right & $98(45.4)$ & $16(44.4)$ & $27(52.9)$ & $11(31.4)$ & $32(43.2)$ & $12(60.0)$ \\
\hline Bilateral & $7(3.2)$ & $3(8.3)$ & $1(2.0)$ & $1(2.9)$ & 0 & $2(10.0)$ \\
\hline \multicolumn{7}{|l|}{ Tumor histology, } \\
\hline Invasive lobular & $6(2.8)$ & 0 & 0 & $3(8.6)$ & $3(4.1)$ & 0 \\
\hline Infl. breast cancer & $9(4.2)$ & $5(13.9)$ & $1(2.0)$ & 0 & $2(2.7)$ & $1(5.0)$ \\
\hline Other & $11(5.1)$ & $1(2.8)$ & $4(7.8)$ & $2(5.7)$ & $4(5.4)$ & 0 \\
\hline $\begin{array}{l}\text { Resection outcome, } \\
\text { n (\%) R0 }\end{array}$ & \multicolumn{6}{|c|}{ Resection outcome, } \\
\hline $\mathrm{R} 1$ & $15(6.9)$ & $2(5.6)$ & $2(3.9)$ & $3(8.6)$ & $5(6.8)$ & $3(15.0)$ \\
\hline $\mathrm{RX}$ & $12(5.6)$ & $1(2.8)$ & $3(5.9)$ & $2(5.7)$ & $6(8.1)$ & 0 \\
\hline \multicolumn{7}{|l|}{ HER2 status, n (\%) } \\
\hline positive & $216(100.0)$ & $36(100.0)$ & $51(100.0)$ & $35(100.0)$ & $74(100.0)$ & $20(100.0)$ \\
\hline negative & 0 & 0 & 0 & 0 & 0 & 0 \\
\hline \multicolumn{7}{|l|}{$\begin{array}{l}\text { Hormone receptor status, } \\
\mathrm{n}(\%)\end{array}$} \\
\hline Positive & $118(54.6)$ & $13(36.1)$ & $22(43.1)$ & $32(91.4)$ & $34(45.9)$ & $17(85.0)$ \\
\hline Negative & $97(44.9)$ & $22(61.1)$ & $29(56.9)$ & $3(8.6)$ & $40(54.1)$ & $3(15.0)$ \\
\hline Unknown & $1(0.5)$ & $1(2.8)$ & 0 & 0 & 0 & 0 \\
\hline
\end{tabular}

n: Number; min: minimum; max: maximum; BMI: Body Mass Index; DCIS: ductal carcinoma in situ; LCIS: lobular carcinoma in situ; CTX: chemotherapy; infl.: inflammatory, R0: no cancer cells seen microscopically at the resection margin; R1: cancer cells present microscopically at the resection margin (microscopic positive margin); RX: other.

HER re-therapy was made by a tumor board in half of the AP $(n=108 ; 50.0 \%)$. Decisive factors for the resumption of retherapy with HER was positive HER2-status in $93.5 \%$ of cases, followed by observed efficacy (47.2\%) and tolerability (46.8\%) of anti-HER2-therapy in the neo-adjuvant or adjuvant pre-treatment. The decision for the accompanying chemotherapy regimen was based upon guideline recommendations in $48.6 \%$ of cases, matched with individual patient performance status in $38.9 \%$ of cases, or the results of studies and publications (36.1\%). Patients were treated over a median of 9.0 mos (range $=0.0-74.7 \mathrm{mos}$ ) with HER, with an initial dose of $8 \mathrm{mg} / \mathrm{kg}$ in $51.4 \%$ of the AP indicating a 3 weekly regimen and in $35.2 \%$ with a starting dose of $4 \mathrm{mg} / \mathrm{kg}$, presumably intended as a weekly regimen. Thirty-eight $\%$ of the AP required a modification of their HER re-therapy, primarily per therapy delay $(11.6 \%)$ or therapy interruption $(10.6 \%)$. The decision for therapy modification was mainly based on the decision of the treating physician (15.3\%), change in body weight $(13.0 \%)$ or patient's request $(1.9 \%)$. HER re-therapy was discontinued in more than half of the patients because of disease progression $(51.4 \%), 10.2 \%$ of the patients died. Physicians decided for $9.7 \%$ of patients to stop HER re-therapy for reasons other than disease progression, while $6 \%$ of patients requested treatment discontinuation. Concomitant treatments were chosen by the treating physician on a patient individual basis resulting in a diversity of treatment 
Table II. Prior treatments in the (neo-) adjuvant setting.

\begin{tabular}{|c|c|c|c|}
\hline Prior Treatments ${ }^{1}$ & $\mathrm{n}(\%)$ & $\begin{array}{l}\text { Treatment duration } \\
\text { mean (STD), mos }\end{array}$ & $\begin{array}{l}\text { Most frequently used } \\
\text { substance(s) n (\%) }\end{array}$ \\
\hline Radiation therapy & $186(86.1)$ & - & - \\
\hline Neoadjuvant anti HER2 therapy & $32(14.8)$ & $6.7(4.64)$ & HER 30 (13.9) \\
\hline Adjuvant anti HER2 therapy & $205(94.9)$ & $11.7(2.51)$ & HER 205 (94.9) \\
\hline Neoadjuvant chemotherapy therapy & $70(32.4)$ & $4.1(1.27)$ & $\begin{array}{c}\text { First neo-adjuvant treatment } \\
\text { Cyclophosphamide } 64(29.6) \\
\text { Epirubicin } 53(24.5) \\
\text { Docetaxel } 52(24.1)\end{array}$ \\
\hline $\begin{array}{l}\text { Neo-adjuvant drug combinations } \\
\text { most frequently used }\end{array}$ & & & $\begin{array}{c}\text { Cyclophosphamide, Docetaxel, Epirubicin } 26 \text { (12.0) } \\
\text { Cyclophosphamide, Docetaxel, Doxorubicin } 12 \text { (5.6) } \\
\text { Cyclophosphamide, Docetaxel, Epirubicin } 7 \text { (3.2), } \\
\text { Fluorouracil } \\
\text { Cyclophosphamide, Epirubicin, Paclitaxel } 7 \text { (3.2) }\end{array}$ \\
\hline Adjuvant chemotherapy therapy & $141(65.3)$ & $4.0(1.84)$ & $\begin{array}{c}\text { First adjuvant treatment } \\
\text { Cyclophosphamide } 117(54.2) \\
\text { Epirubicin } 111(51.4) \\
\text { Fluorouracil } 78(36.1) \\
\text { Docetaxel } 64(29.6)\end{array}$ \\
\hline $\begin{array}{l}\text { Adjuvant drug combinations. } \\
\text { most frequently used }\end{array}$ & & & $\begin{array}{c}\text { Cyclophosphamide, Epirubicin, Fluorouracil } 36 \text { (16.7) } \\
\text { Cyclophosphamide, Docetaxel, Epirubicin, Fluorouracil } 31 \text { (14.4) } \\
\text { Cyclophosphamide, Epirubicin, Paclitaxel } 11(5.1)\end{array}$ \\
\hline Neoadjuvant endocrine therapy & $3(1.4)$ & $19.7(15.51)$ & \\
\hline Adjuvant endocrine therapy & $106(49.1)$ & $36.4(19.40)$ & $\begin{array}{l}\text { Tamoxifen } 25(11.6) \\
\text { Anastrozole } 19(8.8)\end{array}$ \\
\hline
\end{tabular}

n: Number; STD: standard deviation; mos: months; HER: Herceptin; ${ }^{1}$ multiple entries per patient/therapy-line possible.

regimens (see also Table I) including HER monotherapy $(16.7 \%)$, combination of HER and endocrine therapy without concomitant chemotherapy $(16.2 \%)$ or with different chemotherapeutics as single or combination partners $(57.9 \%)$, or HER-treatment concomitantly with chemotherapeutics and endocrine therapy $(9.3 \%)$.

PFS. Altogether 166 (76.9\%) patients from this NIS developed a PFS-event (death or disease progression) with a median PFS of 12.7 mos $(95 \% \mathrm{CI}=10.5-14.8)$. Estimated 6month progression-free rate was $82.0 \%$, and the 12 -month rate was $52.8 \%$.

With respect to the risk factor metastatic disease, differentiated between visceral metastatic (VM), non-visceral metastatic (NVM) and local recurrence (LC), the following distinctions were observed. Median PFS was shortest in the subgroup of patients with VM with 10.2 mos $(95 \% \mathrm{CI}=8.0$ 11.4), while the longest median PFS of 26.1 mos (95\% CI=12.7-not reached) was documented in patients with LC. Accordingly, the lowest 6- (75.7\%) and 12-month $(40.4 \%)$ progression-free rates were seen in the subgroup of patients with VM (Figure 1).

Within the AP, 144 patients with disease-recurrence developed metastases in new organ systems. Primarily affected were lung, bone, and liver in 24, 23 and 20 cases, respectively. Median time to development of metastasis was shortest for peritoneum (4.2 months; range=0.4-11.7 months), and longest for pleural effusion (13.8 months; range=0.2-30.9 months).

A Cox regression analysis assessing the potential influence of patient baseline and tumor characteristics on PFS outcome resulted in VM being of significant impact [hazard ratio $(\mathrm{HR})=2.89(95 \% \mathrm{CI}=1.82-4.59), p<0.001]$ (Table III).

OS. In total, 135 patients $(62.5 \%)$ died during the study with a median OS of $77.3 \mathrm{mos}(95 \% \mathrm{CI}=66.2-88.8)$ and a $12-$ month OS-rate of $100 \%$. The 24-, 36- and 48-month OS rates were $99.5 \%, 92.9 \%$ and $80.3 \%$, respectively.

OS-2. Median OS-2 in the AP was $31.6(95 \% \mathrm{CI}=28.8-38.4)$ mos with 134 events $(62.0 \%)$. The estimated OS-2 rates after one to four years were $82.9 \%, 62.9 \%, 45.3 \%$ and $37.1 \%$, respectively.

OS-2 was also estimated in subgroups of patients with LC, patients with NVM $( \pm \mathrm{LC}$, no $\mathrm{VM})$ and patients with $\mathrm{VM}$ $( \pm \mathrm{NVM} \pm \mathrm{LC})$. In the AP, the median OS-2 was shortest in the VM subgroup with 20.8 mos $(95 \% \mathrm{CI}=17.3-28.8)$ versus in the LC subgroup (not reached) and $49.2 \operatorname{mos}(95 \% \mathrm{CI}=33.1$ not reached) in patients with NVM. Accordingly, the lowest OS-2 rate of $72.0 \%$ at one year was observed in the 


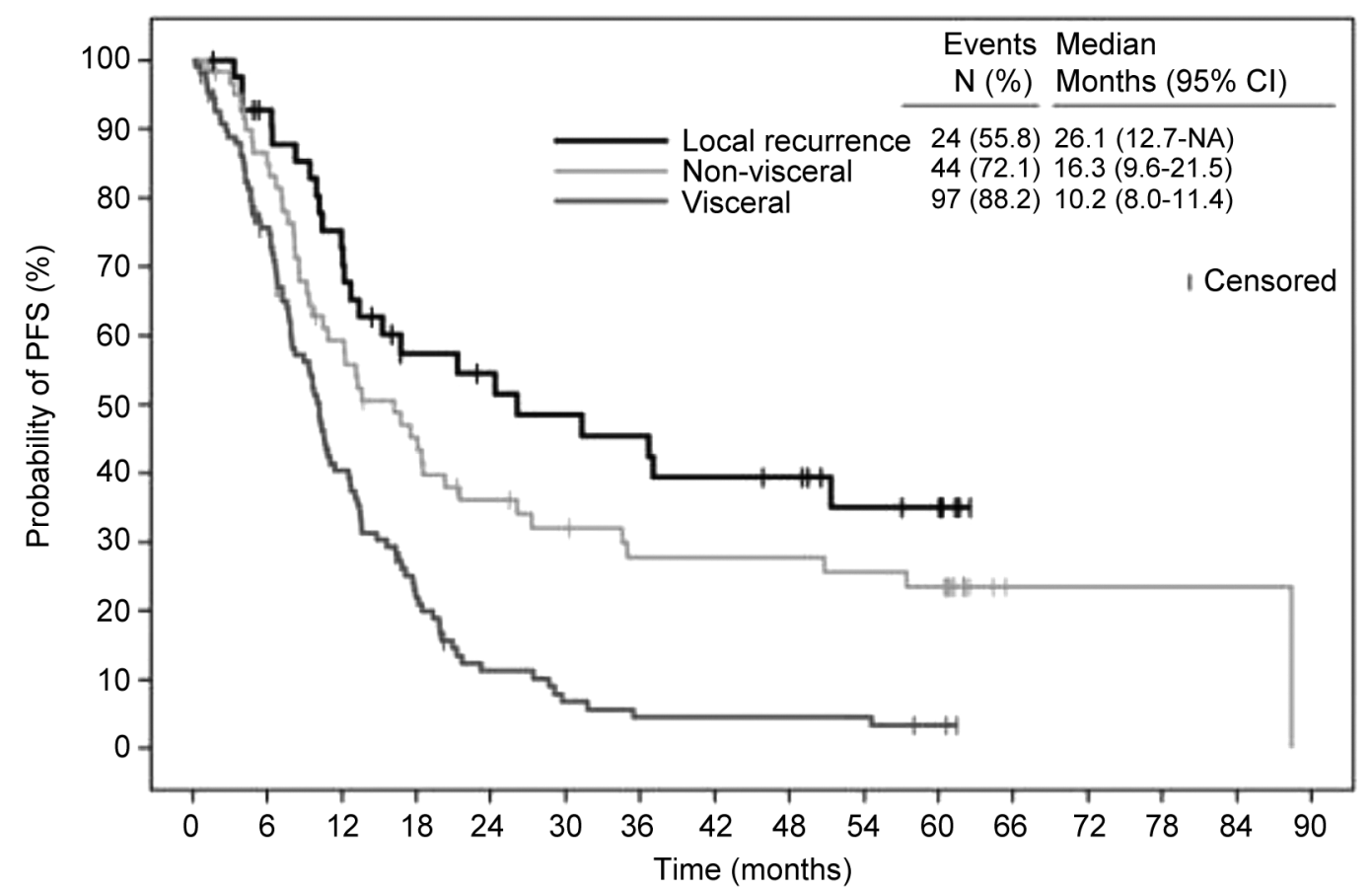

Number at risk

$\begin{array}{rcccccccccccccccc}\text { Local recurrence } & 43 & 37 & 29 & 20 & 18 & 16 & 15 & 13 & 12 & 8 & 7 & 0 & & & \\ \text { Non-visceral } & 61 & 50 & 34 & 25 & 19 & 16 & 13 & 13 & 13 & 12 & 11 & 1 & 1 & 1 & 1 & 0 \\ \text { Visceral } & 110 & 78 & 40 & 21 & 10 & 6 & 4 & 4 & 4 & 4 & 2 & 0 & & & \end{array}$

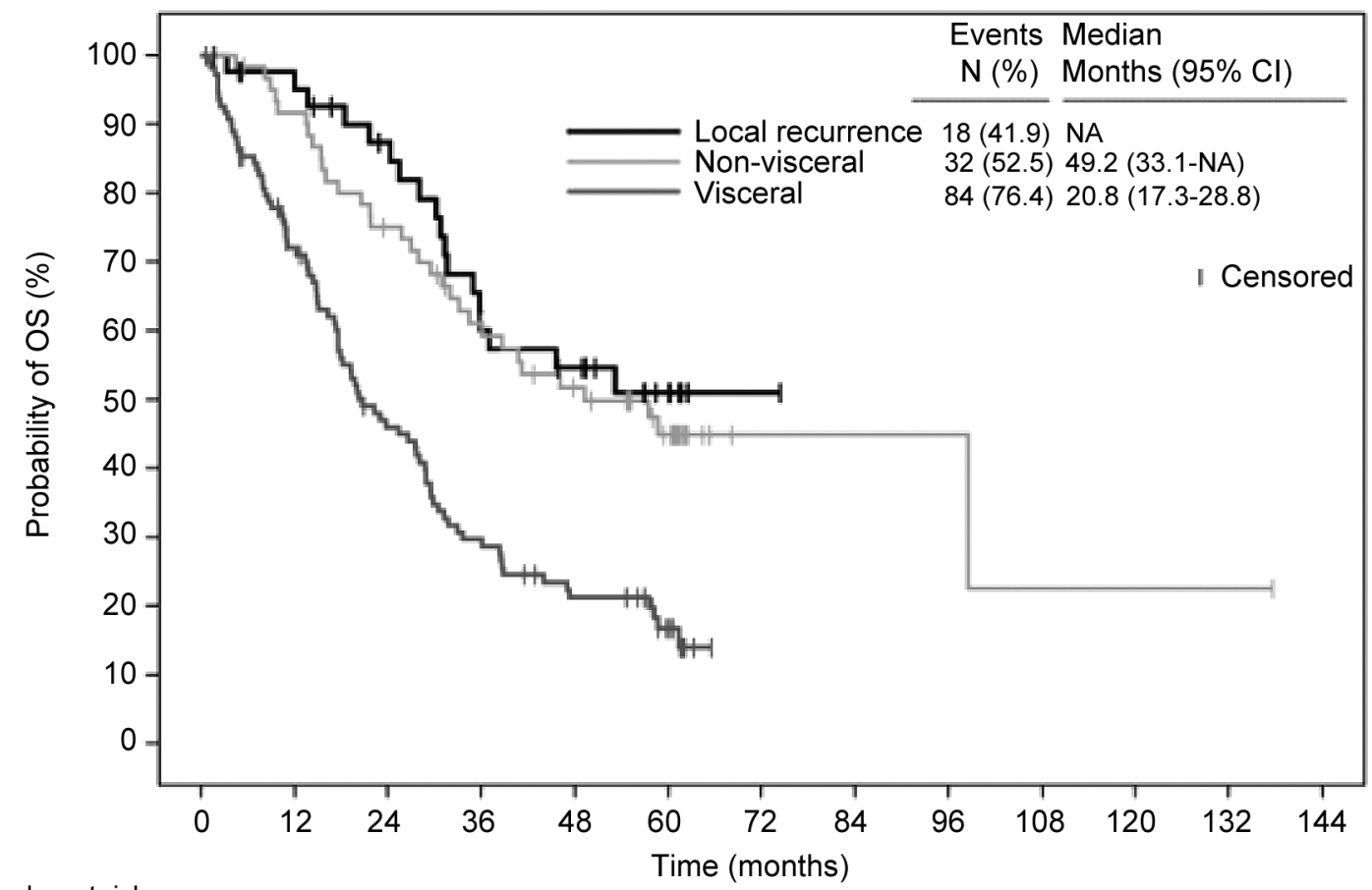

Number at risk

$\begin{array}{rcccccccccccc}\text { Local recurrence } & 43 & 39 & 32 & 22 & 19 & 11 & 1 & 0 & & & & \\ \text { Non-visceral } & 61 & 55 & 44 & 34 & 26 & 17 & 2 & 2 & 2 & 1 & 1 & 1\end{array}$

Figure 1. Progression-free survival (PFS) (left) and overall survival (OS)-2 (right) according to metastatic status. AP: Analysis population; N: number; NA: not reached; CI: confidence interval. OS-2 defined as: time from diagnosis of recurrence or metastasis to death of any cause. 
Table III. Cox regression analysis analyzing potential influence of baseline characteristics (at NIS inclusion) on progression-free survival.

\begin{tabular}{|c|c|c|c|c|}
\hline Parameters & Reference & Hazard ratio (HR) & $95 \% \mathrm{CI}(\mathrm{HR})$ & p-Value \\
\hline \multicolumn{5}{|c|}{ Analysis population (AP): Total $\mathrm{N}=216$} \\
\hline \multicolumn{5}{|c|}{ Cox regression analysis: $\mathrm{N}=212$ [censored: $\mathrm{n}=49(23.1 \%)$ ] } \\
\hline Age at informed consent & -1 year & 1.01 & $1.00-1.02$ & 0.145 \\
\hline BMI & $-1 \mathrm{~kg} / \mathrm{m}^{2}$ & 0.98 & $0.94-1.01$ & 0.165 \\
\hline DFS & -1 month & 1.00 & $0.99-1.01$ & 0.958 \\
\hline Stage at diagnosis III/IV & 0/I/II & 1.06 & $0.76-1.47$ & 0.730 \\
\hline Hormone receptor status negative & Positive & 1.21 & $0.87-1.66$ & 0.255 \\
\hline Non-visceral metastases only & No metastases & 1.46 & $0.88-2.45$ & 0.146 \\
\hline Visceral metastases & No metastases & 2.89 & $1.82-4.59$ & $<0.001 * * *$ \\
\hline
\end{tabular}

N/n: Number; BMI: body mass index; DFS: disease-free survival; HR: hazard ratio; PFS: progression-free survival; $* * * p$-Value $<0.001$.

Table IV. Summary of ADRs and retrospectively documented AEs.

\begin{tabular}{|c|c|c|c|c|c|c|c|}
\hline $\begin{array}{l}\text { ADRs with at least } \\
\text { possible relation* to HER } \\
\text { (throughout the NIS) }\end{array}$ & $\begin{array}{c}\text { Patients } \\
\mathrm{n}\end{array}$ & $\begin{array}{c}\text { Patients } \\
\%\end{array}$ & $\begin{array}{c}\text { Cases } \\
\mathrm{n}\end{array}$ & $\begin{array}{c}\text { Adverse events with no } \\
\text { relation* to HER } \\
\text { documented retroactively } \\
\text { (between July } 2012 \text { and April 2014) }\end{array}$ & $\begin{array}{c}\text { Patients } \\
\mathrm{n}\end{array}$ & $\begin{array}{l}\text { Patients } \\
\%\end{array}$ & $\begin{array}{c}\text { Cases } \\
\mathrm{n}\end{array}$ \\
\hline ADR & 52 & 24.1 & 186 & $\mathrm{AE}$ & 48 & 22.2 & 125 \\
\hline SADR & 17 & 7.9 & 27 & SAE & 22 & 10.2 & 37 \\
\hline $\begin{array}{l}\text { ADR CTCAE } \\
\text { grade } 1\end{array}$ & 24 & 11.1 & 66 & $\begin{array}{l}\text { AE CTCAE } \\
\text { grade } 1\end{array}$ & 15 & 6.9 & 32 \\
\hline $\begin{array}{l}\text { ADR CTCAE } \\
\text { grade } 2\end{array}$ & 35 & 16.2 & 89 & $\begin{array}{l}\text { AE CTCAE } \\
\text { grade } 2\end{array}$ & 27 & 12.5 & 42 \\
\hline $\begin{array}{l}\text { ADR CTCAE } \\
\text { grade } 3 / 4\end{array}$ & 18 & 8.3 & 24 & $\begin{array}{l}\text { AE CTCAE } \\
\text { grade } 3 / 4\end{array}$ & 19 & 8.8 & 38 \\
\hline $\begin{array}{l}\text { ADR CTCAE } \\
\text { grade } 5\end{array}$ & 2 & 0.9 & 4 & $\begin{array}{l}\text { AE CTCAE } \\
\text { grade } 5\end{array}$ & 8 & 3.7 & 8 \\
\hline $\begin{array}{l}\text { ADR leading to } \\
\text { discontinuation of } \\
\text { HER re-therapy }\end{array}$ & 10 & 4.6 & 14 & $\begin{array}{l}\text { AE leading to discontinuation } \\
\text { of HER re-therapy }\end{array}$ & 9 & 4.2 & 9 \\
\hline
\end{tabular}

(s)ADR: (serious) Adverse drug reaction; (s)AE: (serious) adverse event; AP: analysis population; CTCAE v4.03: Common Terminology Criteria for Adverse Events; HER: herceptin; N/n: number; NIS: non-interventional study; *relationship according to reporting physician.

subgroup of patients with VM, and of $46.0 \%, 29.6 \%$ and $21.2 \%$ after two, three and four years (Figure 1).

ORR. ORR was assessed in $81 \%$ of the AP. Tumor response assessed by the treating physician indicated a $9.3 \% \quad(n=20)$ of patients with complete response and 56 patients $(25.9 \%)$ with a partial response, resulting in an ORR of $35.2 \%$. A logistic regression analysis using the same parameters as for the PFS-exploration resulted in no predictive factor for best tumor response.

Further line therapies. $45.4 \%$ of patients had second-line therapy following the end of HER re-therapy; further line treatment documentation declined from line to line. Capecitabine and lapatinib represented the most common treatment reported in second line $(n=21 ; 9.7 \%)$.
Safety. As regulatory obligations changed during this NIS, reporting of safety followed diverging requirements starting with a mere adverse drug reaction (ADR) reporting of HERrelated reactions in the early beginning of data collection. In April 2014, whereat most of the patients had already passed the close observational interval of the NIS, adverse event (AE) reporting was implemented, with a retroactive effect up to July 2012 (Table IV). Final reconciliation efforts consolidated for possible hidden safety information in free text entries and narrative sections.

Most frequently reported ADRs were headache $(n=8$; $3.7 \%)$, chills $(\mathrm{n}=7 ; 3.2 \%)$, diarrhea $(\mathrm{n}=7 ; 3.2 \%)$, and nausea $(\mathrm{n}=7 ; 3.2 \%)$. ADRs with CTCAE grade 3 and higher were chills $(n=3 ; 1.4 \%)$, headache $(n=2 ; 0.9 \%)$ and left ventricular dysfunction $(n=2 ; 0.9 \%)$. Serious cardiac ADRs were 
decreased LVEF in 4 patients (1.9\%) and dyspnea in 3 patients $(1.4 \%)$.

Two patients became pregnant during the study project, one pregnancy was reported with oligohydramnios, assessed as related to HER treatment (ADR CTCAE grade 3). Both patients gave birth to healthy babies with normal size, weight, and APGAR scores.

A total of $135(62.5 \%)$ patients died during the study period, 119 based on progression of their underlying malignant disease $(\mathrm{PoD})$. Twelve patients were reported to have died from an unknown cause of death, two of these 12 patients had (S)AEs before dying (dyspnea and diarrhea, both with no reported relation to HER). Three patients died from "other reasons" [aneurysm $(\mathrm{n}=1)$, rapidly progressing acute myeloid leukemia $(n=1)$, multiple organ failure $(n=1)$, another patient died of an unknown co-morbidity. Two patients $(0.9 \%)$ had fatal SADRs (4 cases): general physical health deterioration, pleural effusion, pneumonia (all reported for one patient) and multiple organ dysfunction syndrome. For both these patients, neoplastic disease was reported as the reason of death.

Retrospective collection of (s)AEs showed the following events rated as not related to HER and quite discriminative from what was reported as ADR: nausea $(\mathrm{n}=7 ; 3.2 \%)$, leukopenia $(\mathrm{n}=6 ; 2.8 \%)$, dyspnea $(\mathrm{n}=5 ; 2.3 \%)$, general physical health deterioration $(\mathrm{n}=5 ; 2.3 \%)$, and polyneuropathy $(\mathrm{n}=5$; $2.3 \%$ ). AEs with seriousness grade 3 or 4 according to CTC AE criteria were leukopenia $(n=4 ; 1.9 \%)$, nausea $(n=3 ; 1.4 \%)$, dyspnea $(\mathrm{n}=2 ; 0.9 \%)$, gastrointestinal pain $(\mathrm{n}=2 ; 0.9 \%)$, urinary tract infection $(\mathrm{n}=2 ; 0.9 \%)$ and vomiting $(\mathrm{n}=2 ; 0.9 \%)$, whereas SAEs not related to HER included a general physical health deterioration $(\mathrm{n}=5 ; 2.3 \%)$, dyspnea $(\mathrm{n}=4 ; 1.9 \%)$, malignant neoplasm progression $(\mathrm{n}=3 ; 1.4 \%)$ and nausea $(\mathrm{n}=3 ; 1.4 \%)$.

AEs prospectively documented after April 2014 occurred in only 3 patients with altogether 5 cases (arthralgia, blood creatinine increased, bone pain, osteonecrosis and syncope, all CTCAE grade $2, \mathrm{n}=1 ; 0.5 \%$ )

Cardiac safety. At least one post baseline measurement of LVEF was documented for $60 \%$ of the AP. LVEF $<50 \%$ was observed in 14 patients and a LVEF-decrease of more than $10 \%$ compared to baseline was documented in 30 patients. Decreased LVEF was reported as SADR in 4 patients (1.9\%) and in 5 patients $(2.3 \%)$ as an ADR, while $3(1.4 \%)$ patients had SADR dyspnea.

\section{Discussion}

Despite the huge therapeutic progress after introducing antiHER2-therapy into early breast cancer treatment, unfortunately recurrence occurs with a cumulative hazard for recurrence-free survival (RFS) in $11-17.5 \%$ of patients during the first 5 years, depending on $\mathrm{HR}+\mathrm{HR}$ - disease and other risk factors $(4,15$,
16). Results from our NIS show different outcomes in terms of PFS and OS based on the metastatic status. As metastatic status differs, combination treatment with anti-HER2 re-therapy differs. Patients with visceral metastases were preferentially treated strictly according to HER label, whereas patients with non-visceral metastases or local recurrence were treated with regimens ranging from HER monotherapy to labelled combination with taxanes with or without endocrine therapy (results not shown). Thus, it seems that treatment decisions besides guideline consideration (17-19) take into account the individual patient situation as well as tumor and baseline characteristics. Every second treatment decision was made by a tumor board. Summarizing the patient population and matching PFS and OS results from this NIS with the randomized controlled trial RHEA [PFS NIS 12.7 vs. RHEA 8.0 mos, mOS-2 NIS 31.6 mos vs. RHEA 25.0 mos (endpoint was not defined as OS-2 directly) (11)], a positive transfer of study data into real world evidence seems to be justified. The same applies when looking at the results of the original registration study for HER in metastatic breast cancer resulting in a mPFS of 7.4 mos and a median OS of 25.1 mos (1). These results are similar to those from the controlled RHEA trial (11) and by trend somewhat longer in our NIS. Safety results from this NIS, show a certain effect of underreporting, as it comes with daily routine. This may be also transferable to cardiac monitoring, as for example, recommended assessment intervals were not followed consistently - although one special focus was on cardiac safety $(20,21)$. Data reflect physician's retention to safety reporting in clinical routine, nevertheless patients should be monitored for cardiac safety and emphasis was put at this topic.

Our RW data have limitations including the heterogenous patient distribution; some results were based on retrospective data collection like DFS and OS; there was a tendency of underreporting of safety of HER re-therapy. Unlike in controlled clinical trials, tumor response assessment was neither based on RECIST criteria (22) nor a confirmatory second visit. The statistically planned overall sample size was not achieved due to a higher rate of patient ineligibility than anticipated.

Treatment guidelines changed throughout the long realization time of this NIS (17-19). For example, new treatment options like the dual blockade with pertuzumab (Perjeta ${ }^{\circledR}$ ) and trastuzumab or the treatment with the antibody-drug conjugate of trastuzumab with emtansine $\left(\right.$ Kadcyla $\left.^{\circledR}\right)$ in metastatic as well as in early breast cancer provided new options (23). Data from these new therapy options (24-26) or data from HER treatment beyond progression (27) cannot be directly compared to results from this NIS. In consequence, HER proved to be an effective and well tolerated re-treatment for first-line patients with HER2positive breast cancer relapsing after (neo-) adjuvant treatment with HER in a RW setting. 


\section{Data Statement}

Qualified researchers may request access to individual patient level data through the clinical study data request platform (www.clinical studydatarequest.com). Further details on Roche's criteria for eligible studies are available here: https://clinicalstudydatarequest.com/StudySponsors/Study-Sponsors-Roche.aspx. For further details on Roche's Global Policy on the Sharing of Clinical Information and how to request access to related clinical study documents, see here: https://www.roche.com/research_and_development/who_we_are_how _we_work/clinical_trials/our_commitment_to_data_sharing.htm

\section{Conflicts of Interest}

Lars Hanker received advisory board fees and honoraria from Roche, Astra Zeneca, Tesaro/GSK, Pharma Mar, Amgen, Novartis. Achim Rody received advisory board fees and honoraria from Roche, Astra Zeneca, Genomic Health, MSD, Pfizer, Novartis, Hexal, Amgen, Lilly, EiSAI. Frank Förster received Honoraria and advisory board fees for Roche, Novartis, and Pfizer. Jan Schröder received advisory board fees and honoraria from IOMEDICO, Celgene, Roche, BMS, Clovis Oncology GmbH, Boehringer Ingelheim, Amgen, Novartis, MSD, AOP. Tobias Hesse reports personal fees and non-financial support from Roche and Eisai, personal fees from Novartis and Pfizer and non-financial support from MSD. Thomas Hitschold and Andrea Grafe have no conflicts of interest to declare. Claus Lattrich is an employee of the Roche Pharma AG.

\section{Authors' Contributions}

Drafting of the manuscript, review, revision, and submission was done by the Authors. All Authors of the manuscript, i.e. Hanker LC, Förster F, Schröder J, Grafe A, Hitschold T, Hesse T, Lattrich C, Rody A contributed to the conception and design of the study, to the generation, collection, assembly, analysis and/or interpretation of data and to the drafting or revision of the manuscript. All Authors approved the final version and submission of the manuscript.

\section{Acknowledgements}

LCH was scientific lead of the NI study. Third party medical writing was provided by Dorothee Schneider, S\&P GmbH.

\section{Funding}

This non-interventional study was funded by Roche Pharma AG Germany.

\section{References}

1 Slamon DJ, Clark GM, Wong SG, Levin WJ, Ullrich A and McGuire WL: Human breast cancer: correlation of relapse and survival with amplification of the HER-2/neu oncogene. Science 235(4785): 177-182, 1987. PMID: 3798106. DOI: 10.1126/science. 3798106

2 Ross JS, Fletcher JA, Linette GP, Stec J, Clark E, Ayers M, Symmans WF, Pusztai L and Bloom KJ: The HER-2/neu gene and protein in breast cancer 2003: Biomarker and target of therapy. Oncologist 8(4): 307-325, 2003. PMID: 12897328. DOI: $10.1634 /$ theoncologist.8-4-307

3 Ross JS, Slodkowska EA, Symmans WF, Pusztai L, Ravdin PM and Hortobagyi GN: The HER-2 receptor and breast cancer: ten years of targeted anti-HER-2 therapy and personalized medicine. Oncologist 14(4): 320-368, 2009. PMID: 19346299. DOI: 10.1634/theoncologist.2008-0230

4 Dawood S, Broglio K, Buzdar AU, Hortobagyi GN and Giordano SH: Prognosis of women with metastatic breast cancer by HER2 status and trastuzumab treatment: an institutionalbased review. J Clin Oncol 28(1): 92-98, 2010. PMID: 19933921. DOI: $10.1200 / J C O .2008 .19 .9844$.

5 Cobleigh MA, Vogel CL, Tripathy D, Robert NJ, Scholl S, Fehrenbacher L, Wolter JM, Paton V, Shak S, Lieberman G and Slamon DJ: Multinational study of the efficacy and safety of humanized anti-HER2 monoclonal antibody in women who have HER2-overexpressing metastatic breast cancer that has progressed after chemotherapy for metastatic disease. J Clin Oncol 17(9): 2639-2648, 1999. PMID: 10561337. DOI: 10.1200/JCO.1999.17.9.2639

6 Slamon DJ, Leyland-Jones B, Shak S, Fuchs H, Paton V, Bajamonde A, Fleming T, Eiermann W, Wolter J, Pegram M, Baselga $J$ and Norton L: Use of chemotherapy plus a monoclonal antibody against HER2 for metastatic breast cancer that overexpresses HER2. N Engl J Med 344(11): 783-792, 2001. PMID: 11248153 . DOI: 10.1056/NEJM200103153441101

7 Marty M, Cognetti F, Maraninchi D, Snyder R, Mauriac L, Tubiana-Hulin M, Chan S, Grimes D, Antón A, Lluch A, Kennedy J, O’Byrne K, Conte PF, Green M, Ward C, Mayne K and Extra J-M: Randomized phase II trial of the efficacy and safety of trastuzumab combined with docetaxel in patients with human epidermal growth factor receptor 2-positive metastatic breast cancer administered as first-line treatment: the M77001 study group. J Clin Oncol 23(19): 4265-4274, 2005. PMID: 15911866. DOI: $10.1200 / \mathrm{JCO} .2005 .04 .173$

8 Perez EA, Romond EH, Suman VJ, Jeong JH, Sledge G, Geyer CE, Martino S, Rastogi P, Gralow J, Swain SM, Winer, EP, Colon-Otero G, Davidson NE, Mamounas E, Zujewski JA and Wolmark N: Trastuzumab plus adjuvant chemotherapy for human epidermal growth factor receptor 2-positive breast cancer: planned joint analysis of overall survival from NSABP B-31 and NCCTG N9831. J Clin Oncol 32(33): 3744-3752, 2014. PMID: 25332249. DOI: 10.1200/JCO.2014.55.5730

9 Slamon D, Eiermann W, Robert N, Pienkowski T, Martin M, Press M, Mackey J, Glaspy J, Chan A, Pawlicki, M, Pinter T, Valero V, Liu M-C, Sauter G, Minckwitz, G von, Visco F, Bee V, Buyse M, Bendahmane B, Tabah-Fisch I, Lindsay M-A, Riva A and Crown J: Adjuvant trastuzumab in HER2-positive breast cancer. N Engl J Med 365(14): 1273-1283, 2011. PMID: 21991949. DOI: 10.1056/NEJMoa0910383

10 Paik S, Kim C and Wolmark N: HER2 status and benefit from adjuvant trastuzumab in breast cancer. N Engl J Med 358(13): 1409-1411, 2008. PMID: 18367751. DOI: 10.1056/NEJMc0801440

11 Láng I, Bell R, Feng FY, Lopez RI, Jassem J, Semiglazov V AlSakaff N, Heinzmann D and Chang J: Trastuzumab retreatment after relapse on adjuvant trastuzumab therapy for human epidermal growth factor receptor 2-positive breast cancer: Final results of the retreatment after herceptin adjuvant trial. Clin Oncol 26(2): 81-89, 2014. PMID: 24051172. DOI: 10.1016/j.clon.2013.08.011 
12 Kaplan EL and Meier P: Nonparametric estimation from incomplete observations. J Am Stat Assoc 53(282): 457-481, 1958. DOI: $10.2307 / 2281868$

13 Cox DR: Regression models and life-tables. J R Stat Soc B 34(2): 187-220, 1972.

14 Chumsri S, Li Z, Serie DJ, Mashadi-Hossein A, Colon-Otero G, Song N, Pogue-Geile KL, Gavin PG, Paik S, Moreno-Aspitia A, Perez EA and Thompson EA: Incidence of late relapses in patients with her2-positive breast cancer receiving adjuvant trastuzumab: Combined analysis of NCCTG N9831 (Alliance) and NRG Oncology/NSABP B-31. J Clin Oncol, 2019. PMID: 31622131. DOI: $10.1200 /$ JCO 19.00443

15 Tripathy D, Rugo HS, Kaufman PA, Swain S, O’Shaughnessy J, Jahanzeb M, Mason G, Beattie M, Yoo B, Lai C, Masaquel A and Hurvitz S: The SystHERs registry: an observational cohort study of treatment patterns and outcomes in patients with human epidermal growth factor receptor 2-positive metastatic breast cancer. BMC Cancer 14: 307, 2014. PMID: 24885258. DOI: 10.1186/1471-2407-14-307

16 Partridge AH, Gelber S, Piccart-Gebhart MJ, Focant F, Scullion M, Holmes E, Winer EP and Gelber RD: Effect of age on breast cancer outcomes in women with human epidermal growth factor receptor 2-positive breast cancer: results from a herceptin adjuvant trial. J Clin Oncol 31(21): 2692-2698, 2013. PMID: 23752109. DOI: $10.1200 /$ JCO.2012.44.1956

17 Deutsche Krebsgesellschaft, Deutsche Krebshilfe: S3-Leitlinie Mamma. Früherkennung, Diagnose, Therapie und Nachsorge des Mammakarzinoms. AWMF (Leitlinienprogramm Onkologie). AWMF Registernummer: 032-045O. Available at: http://www.leitlinienprogramm-onkologie.de/leitlinien/ mammakarzinom/ [Last accessed on 20.05.2019]

18 Liedtke C, Jackisch C, Thill M, Thomssen C, Müller V and Janni $\mathrm{W}$ : AGO recommendations for the diagnosis and treatment of patients with early breast cancer: Update 2018. Breast Care 13(3): 196-208, 2018. PMID: 30069181. DOI: 10.1159/000489329

19 Thill M, Liedtke C, Müller V, Janni W and Schmidt M: AGO recommendations for the diagnosis and treatment of patients with advanced and metastatic breast cancer: Update 2018. Breast Care 13(3): 209-215, 2018. PMID: 30069182. DOI: $10.1159 / 000489331$

20 Advani PP, Ballman KV, Dockter TJ, Colon-Otero G and Perez EA: Long-term cardiac safety analysis of NCCTG N9831 (alliance) adjuvant trastuzumab trial. J Clin Oncol 34(6): 581587, 2016. PMID: 26392097. DOI: 10.1200/JCO.2015.61.8413

21 Procter M, Suter TM, Azambuja E de, Dafni U, van Dooren V, Muehlbauer S, Climent MA, Rechberger E, Liu WT-W, Toi M, Coombes RC, Dodwell D, Pagani O, Madrid J, Hall M, Chen SC, Focan C, Muschol M, van Veldhuisen DJ and Piccart-Gebhart MJ: Longer-term assessment of trastuzumab-related cardiac adverse events in the Herceptin Adjuvant (HERA) trial. J Clin Oncol 28(21): 3422-3428, 2010. PMID: 20530280. DOI: 10.1200/JCO.2009.26.0463
22 Kim JH, Min SJ, Jang HJ, Cho JW, Kim SH and Kim HS: Comparison of RECIST 1.0 and RECIST 1.1 in patients with metastatic cancer: A pooled analysis. J Cancer 6(4): 387-393, 2015. PMID: 25767610. DOI: $10.7150 /$ jca. 11316

23 Lavaud P and Andre F: Strategies to overcome trastuzumab resistance in HER2-overexpressing breast cancers: focus on new data from clinical trials. BMC Med 12: 132, 2014. PMID: 25285786. DOI: 10.1186/s12916-014-0132-3

24 Swain SM, Baselga J, Kim SB, Ro J, Semiglazov V, Campone M, Ciruelo E, Ferrero J-M, Schneeweiss A, Heeson S, Clark E, Ross G, Benyunes MC and Cortés J: Pertuzumab, trastuzumab, and docetaxel in HER2-positive metastatic breast cancer. N Engl J Med 372(8): 724-734, 2015. PMID: 25693012. DOI: 10.1056/NEJMoa1413513

25 Geyer CE, Forster J, Lindquist D, Chan S, Romieu CG, Pienkowski T, Jagiello-Gruszfeld A, Crown J, Chan A, Kaufman B, Skarlos D, Campone M, Davidson N, Berger M and Oliva C: Lapatinib plus capecitabine for HER2-positive advanced breast cancer. N Engl J Med 355(26): 2733-2743, 2006. PMID: 17192538. DOI: 10.1056/NEJMoa064320

26 Blackwell KL, Miles D, Gianni L, Krop IE, Welslau M, Baselga J, Pegram MD, Oh D-Y, Dieras V, Olsen SR, Fang L, Lu MW, Guardino E and Verma S: Primary results from EMILIA, a phase III study of trastuzumab emtansine (T-DM1) versus capecitabine (X) and lapatinib (L) in HER2-positive locally advanced or metastatic breast cancer (MBC) previously treated with trastuzumab (T) and a taxane. J Clin Oncol 30(18_suppl): LBA1-LBA1, 2012. PMID: 28140802. DOI: 10.1200/jco.2012.30.18_suppl.lba1

27 Waddell T, Kotsori A, Constantinidou A, Yousaf N, Ashley S, Parton M, Allen M, Starling N, Papadopoulos P, O'Brien M, Smith I and Johnston S: Trastuzumab beyond progression in HER2-positive advanced breast cancer: The Royal Marsden experience. Br J Cancer 104(11): 1675-1679, 2011. PMID: 21522147. DOI: $10.1038 /$ bjc. 2011.138
Received May 26, 2020

Revised June 10, 2020

Accepted June 11, 2020 